\title{
ACCURACY OF THE SOIL SEALING ENHANCEMENT PRODUCT FOR POLAND
}

\author{
MaŁgorzata Krónczyńska ${ }^{1}$, Agnieszka Soszyńska ${ }^{1}$, Piotr Pabjanek ${ }^{1}$, Ewa WilK ${ }^{1}$, \\ Pavol HurbaneK ${ }^{2}$, Konstantin Rosina ${ }^{3}$ \\ ${ }^{1}$ Department of Geoinformatics, Cartography and Remote Sensing, University of Warsaw, Poland \\ ${ }^{2}$ Geography Department, Catholic University in Ružomberok, Slovakia \\ ${ }^{3}$ Institute of Geography, Slovak Academy of Sciences, Bratislava, Slovakia
}

Manuscript received: April 27, 2016

Revised version: August 12, 2016

\begin{abstract}
Krówczyńska M., Soszrńska A., Pabjanek P., Wilk E., Hurbanek P., Rosina K., 2016. Accuracy of the soil sealing enhancement product for Poland. Quaestiones Geographicae 35(3), Bogucki Wydawnictwo Naukowe, Poznań, pp. 89-95, 4 figs, 1 table.

AвSTRACT: Increasing urbanization results in constant enlarging of the artificial area closed to water infiltration. In 2006-2008, the Soil Sealing Enhancement (SSE) database was the part of the GMES Fast Track Service on Land Monitoring. The accuracy of the final product set by the authors should reach at least $85 \%$. Orthorectified high resolution aerial photos of Poland were used to develop reference data constituting 20,000 random samples around the country. In each sample, the points were classified into three possible surface classes: natural, artificial and semi-sealed. Comparison of reference data to original project statistics revealed the values of accuracy, commission and omission errors in the SSE dataset. Although, SSE accuracy in Poland fulfils the criteria set by SSE authors with overall accuracy of 99.5\%, the individual analysis for each category reveals many weaknesses. Preliminary interpretation of mistakes leads to the conclusion that the spatial resolution of pictures used in the SSE project is insufficient. In several cases, validation proved that omission errors were made in relation to construction sites or recently constructed buildings. It should be stated that the accuracy of SSE product for Poland should be treated as the maximum value of impervious surfaces.
\end{abstract}

KEY WORDS: soil sealing, impervious surfaces, land cover, Poland

Corresponding author: Małgorzata Krówczyńska (e-mail: mkrowczynska@uw.edu.pl)

\section{Introduction}

Developing urbanization and increasing acquisition of green areas for construction purposes results in constant enlargement of artificial areas closed to water infiltration. Estimation of impervious areas is an important issue, for it is an indicator of the level of human pressure on the natural environment and informs of the water flow capacity in the hydrological cycle of an area (Flinker 2010).

One of the effects of the soil sealing described in literature is the perturbation of natural outflow of rainwater (Klosterman 2012). This tendency seems problematic, especially after storms that release grand amount of water in a short period of time. When falling on natural surfaces, water percolates and the outflow is meagre. In built-up areas, however, almost all rain water resources need to be held in the sewage system, the capacity of which is limited. Furthermore, these consequences lead to an increase of flood risk, by wasting soil under the artificial surfaces and pollution of water resources (also potable) by addition of the substances coming from anthropogenic 
infrastructure, such as calcium, sodium, chloride, heavy metals, i.e. nickel, chromium, copper and zinc. The effects mentioned above change the natural environment in the region, its microclimate and the state of natural fauna and flora (Brabec et al. 2002, Yang et al. 2003, Weng 2007, Flinker 2010).

The subject of soil imperviousness has been capturing attention since the 1990s. In 2002, the European Commission (EC) acknowledged soil sealing as one of the major threats for soils, along with erosion, salinity and land sliding (Tóth 2006). General information on soil sealing in Europe was first published by the EC in Soil Sealing Guidelines treating about causes, results, and possible mitigation practices of the soil sealing (European Commission 2012a). Studies for the current imperviousness situation in Europe in this report were based on CORINE Land Cover (CLC) project information. The purpose of CLC was to create an international database with land cover information. Until now, several editions of the database were created (European Commission 2012b).

Creating databases of impervious surfaces is a novel idea supporting the management process of impervious surfaces and land development plans. The first database containing information on soil sealing was the United States National Land Cover Database from 2001 (Maucha et al. 2010). A couple of years later, a similar database containing a layer of impervious surfaces, was derived, basing on CLC project for Europe (Prokop 2012).

SSE project is a part of the GMES-FTS LM (now: Copernicus - The European Earth Observation Programme) created between 2006 and 2008 (Kopecky, Kahaba 2006). To produce the Soil Sealing Layer (SSL), satellite images coming from SPOT 4 HRVIR, SPOT 5 HRG (around 3000 images altogether) and IRS-P6 LISS III (around 800 images) were used. All the pictures were taken in $2006 \pm 1$ year (European Environment Agency 2006). The product of the classification of Soil Sealing Layer (SSL) is the database, and two maps: SSE2006 with $20 \mathrm{~m} \times 20 \mathrm{~m}$ spatial resolution and a generalized image called SSE100, based on the first product with a spatial resolution of $100 \mathrm{~m} \times 100 \mathrm{~m}$.

The subject of the work is to assess the accuracy of SSL product for Poland. Determining the
SSL for country is an important issue for managing spatial planning and conducting environmental policies. SSE project enables to provide an overview of the whole territory of Europe, and therefore assessment for each country is helpful to improve updates of the project. Similar studies have been undertaken for some other countries (e.g. Czech Republic and Slovakia), but the territory of Poland is bigger and has a significant part of the natural surfaces. These features can lead to more specific conclusions of the general assessment of SSE.

\section{Methodology and data used}

SSL accuracy assessment for Poland was made according to the method proposed by Hurbánek et al. (2010). Their solution consisted of a comparison between SSL data and reference data. Reference data consisted of 2,000,000 reference points in 20,000 samples randomly placed around the territory of Poland. Areas where the orthophotomap was not within the interval of 1 year older and newer than the SSL, were omitted in order to minimize the dissimilarities in land cover.

According to the method of Hurbánek et al. (2010), each analyzed point (of 2,000,000 points in the whole dataset) were classified by the user into three classes, obtaining values: 0 - natural surfaces, 1 - sealed surfaces and 2 - semi-sealed surfaces. Points with value 2 were subject to the additional interpretation. It was decided at the later stage of the study to assign them value 0 natural surfaces. This approach came from the uncertainty in class definition as well as the exact procedure of the identification of sealed surfaces in the SSL production. The whole study was undertaken with the use of ArcMap 10.1 software with a VBA plug-in, which was created for the case of this analysis. The used orthophotmap was derived from the National Registry of Poland (Polish geoportal).

The survey did not comprise the whole territory of Poland due to the lack in the national resources of the orthophotomap fulfilling the selected criteria Figure 1, ie. areas where the orthophotomap was not within the interval of 1 year older and newer than the SSL. The Polish geoportal provided the basemap in the PUWG 1992 projection. For 


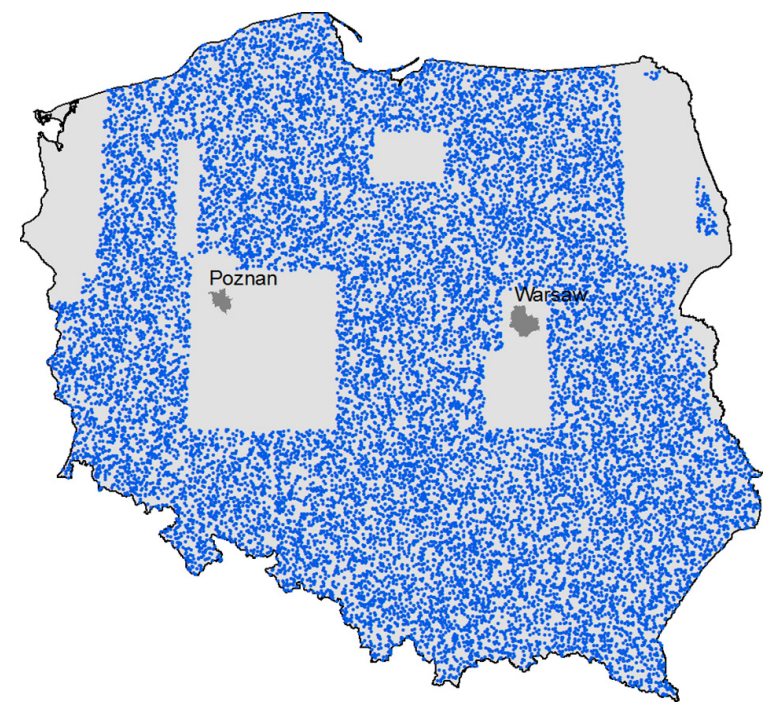

Fig. 1. Location of 20,000 random samples.

the purposes of the project it was transformed to LAEA by ArcMap, in which SSL was applied.

The following step was to sum up the sealing value in each sample and compare it with corresponding data from the SSE project.

Reference data samples had exactly the same size and location as samples derived from SSE data. Subsequently, sealing values from reference data and original product were compared to designate the accuracy of the product.

After completing the comparison, both datasets were divided into 6 intervals based on the imperviousness level: 0\%, 1-29\%, 30-49\%, 50-79\%, $80-99 \%, 100 \%$. These levels were established on the basis of the methodology of Hurbánek et al. (2010). In each interval, the following statistics were calculated using confusion matrix: commission and omission error, user's accuracy, producer's accuracy; for the whole dataset, overall accuracy and Cohen's-Kappa coefficient (Congalton, Green 1993).

All statistical indicators were calculated for two cases depending on number of intervals, in the first case it was two $(<80 \%$ of sealed surface in the cell as non built-up area and $80-100 \%$ of sealed surfaces in the cell as built-up area), the second case consisted of six intervals described.

\section{Results}

When two intervals were taken into consideration, only 130 cells $(0.65 \%)$ in the survey area were classified as sealed, moreover this number was even smaller in the reference dataset: 25 cells $(0.13 \%)$. The number representing natural, non built-up class was significantly bigger: SSL classified 19,870 cells as natural $(99.35 \%)$, whereas reference data allocated 19,975 cells $(99.87 \%)$ to this class. The disproportion between two classes is notable and influences user's and producer's accuracy results.

User's and producer's accuracy for the nonsealed class amounts to almost $100 \%$, the corresponding commission error amounts to $0.01 \%$ and the omission error $-4 \%$. In the sealed class, however, the obtained results were different. While the producer's accuracy remains very high $(96 \%)$, the user's accuracy drops $(18.46 \%)$. This situation is caused by the overestimation of the sealed class where SSL data found 130 cells belonging to this interval, while the reference data classified there amounted to 25 . Underestimation of imperviousness appeared in only one case, which resulted in $4 \%$ omission error.

In the undertaken survey the number of cells in sealed classes is overestimated by SSL data. In both databases, natural surfaces are the most numerous group. Moreover, the validation proved that the number of samples in this class was overestimated $(18,557$ cells in SSL in comparison to 16,457 cells in reference data). For the second interval (1-29\%) 812 samples in SSL data were classified as non-sealed while validation assigned 3,230 to this class. The underestimation is observed only in the second interval, the following classes are characterized by overestimation of SSL data over the reference data. The difference between the SSL and reference data decreases proportionally to the number of samples assigned to each class, but inversely to the level of sealing. In the validation no cells were classified as fully sealed, whereas SSE assigned 21 cells into this interval.

Improperly assigned cells are distributed proportionally around the classes where they belong. The SSE classification results in substantial number of errors in the first sealed class. In this case, misclassified cells were assigned to nonsealed class. The omission of 2,418 cells indicates an important weakness of the classification.

SSL overestimated the level of imperviousness in the classes where the number of samples were underestimated (with the exception of the first class described above) 
is usually smaller than the number of overestimated cells. Decreasing number of mistakes is related with the increasing percentage of imperviousness. The distribution of errors proves overstatement of the imperviousness level in the Soil Sealing Enhancement classification.

The non-sealed class $(0 \%)$ is characterized by high user's and producer's accuracy (respectively $88.06 \%$ and $99.30 \%)$, low omission error $(0.70 \%)$ and a relatively small commission error $(11.94 \%)$. It is however important to point out the grand preponderance of this class compared to the other classes - in the reference dataset, these cells comprise $82 \%$ of all samples. Very high accuracy of this class combined with its high number can lead to the misinterpretation of the overall picture.

The following interval (1-29\%) is incomparable with the described natural class as far as the quantity is concerned. We can observe a high rate of user's accuracy $(84.85 \%)$, but very low producer's accuracy $(21.33 \%)$. This last result comes from the underestimation of that class. In SSE data 104 cells from 1-29\% class, containing small sealed surfaces, were classified as natural surfaces. The number of underestimated cells in general in this interval was constituted $89.6 \%$ mistakes in this class.

Omission error in this class is the highest in all classes: $78.67 \%$. On the other hand, the commission error is rather low. This situation comes from the preponderance of the samples classified as natural $(2,207$ cells) to the samples in which imperviousness was overestimated (332 cells altogether).

The following imperviousness interval (30$49 \%$ ) has also been overestimated: validation assigned 192 samples, whereas SSL data classified 293 cells into this class. Both user's and producer's accuracy rates are low (respectively 17.06\% and $26.04 \%$ ), while omission and commission errors, which are inversely proportional to accuracy values, are rather high.

96 cells were validated to the fourth class (50$79 \%)$, whereas in the SSE data this interval contains 208 samples. As observed previously, user's and producer's accuracy rates are low (12.02\% for user's accuracy and $26.04 \%$ for producer's accuracy). The mistakes are distributed similarly to the previous interval: in 182 cells the imperviousness level is overstated effecting in high commission error; 62 samples, which actually belonged
Table 1. Overall results of the classification.

\begin{tabular}{|l|r|}
\hline Overall accuracy (two intervals) & $99,47 \%$ \\
\hline Overall accuracy (six intervals) & $85,58 \%$ \\
\hline Cohen's-Kappa coefficient (two intervals) & $30,82 \%$ \\
\hline Cohen's-Kappa coefficient (six intervals) & $37,24 \%$ \\
\hline
\end{tabular}

to this interval, were put in the next sealed class (80-99\%), causing high omission error (underestimation appears in 9 cases).

The fifth interval's (80-99\%) statistics are slightly changed in comparison to other classes. In SSL data, 109 samples were assigned to this class, while in ground truth only 25 cells belonged there. User's accuracy is low (10.09\%), but producer's accuracy rate is higher $(44 \%)$ than in the fourth class. Consequently, the omission error is lower than in the fourth class (56\%), but commission error is high (89.91\%). In SSE dataset 13 samples belonging to this interval were classified as completely sealed $(100 \%)$.

Reference data classified no samples as fully sealed, but SSE data assigned 21 cells into this class. Due to this, the statistics of this class are falsified: $100 \%$ of producer's accuracy comes from lack of omission error. User's accuracy is the indicator showing better representation of this class $(0 \%)$.

Results of overall accuracy for both cases (two and six intervals) are high and above the level set initially by the authors of the project (Table 1). The last indicator counted was the Cohen'sKappa coefficient. The result presented above (Table 1) suggests a low compatibility of two datasets.

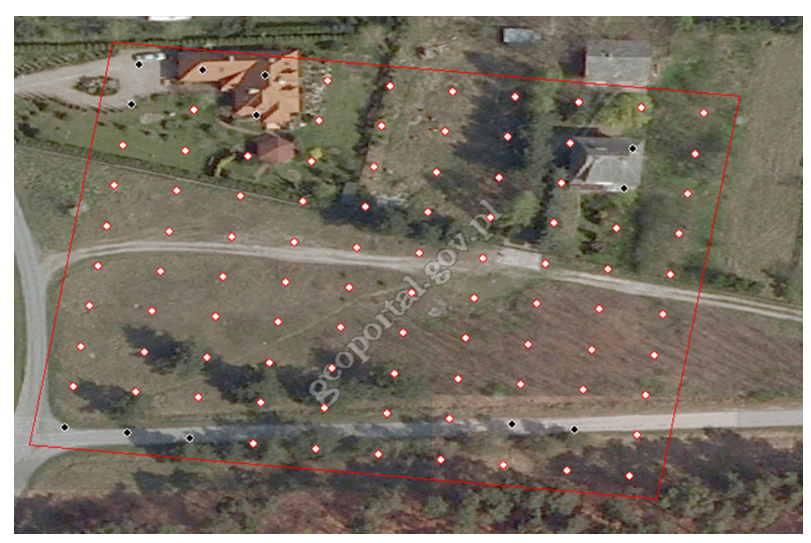

Fig. 2. Impervious surfaces misclassification (small buildings, narrow roads). Impervious surfaces marked with black dots, natural surfaces with white ones. SSL - 0\%, GT - $12 \%$. 


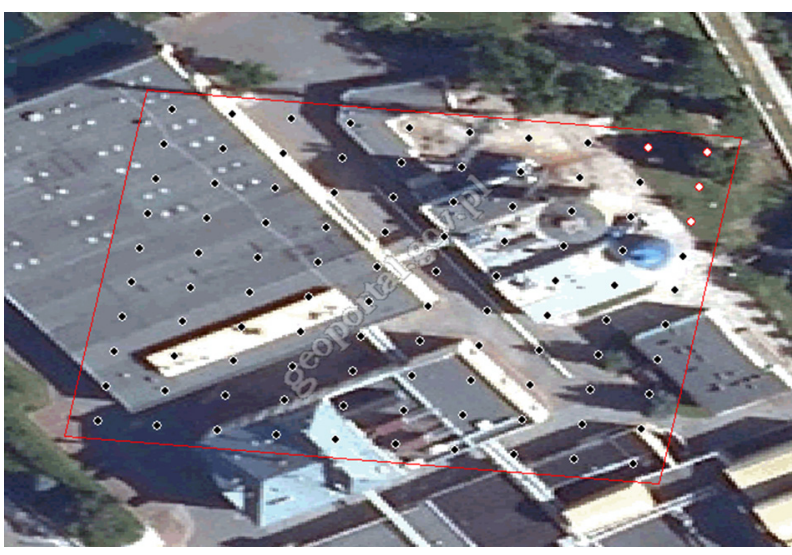

Fig. 3. Impervious surfaces misclassification (nonsealed surfaces classified by SSE as sealed) SSL $100 \%$, GT - $96 \%$.

The most probable cause for the vast majority of mistakes is low ground resolution of satellite imagery used in the whole process of automatic classification $(20 \mathrm{~m} \times 20 \mathrm{~m})$. It resulted in the generalization and skipping of small areas of impervious surfaces (marked with black spots), like small buildings, narrow roads, etc., which were omitted and treated as natural surfaces (Fig. 2).

Low ground resolution and generalization could also result in the opposite misclassification where small natural surfaces were omitted and sealing level was overestimated (Fig. 3).

Overestimation due to pixel size also appeared in other sealing classes: in $50-79 \%$ interval, 5 samples were classified as completely sealed, and 4 of those omitted small natural areas, such as tree crowns. In cities where trees grow in little spaces among pavements or parking lots, the branches actually cover mostly sealed areas, which also has led to the misclassification.

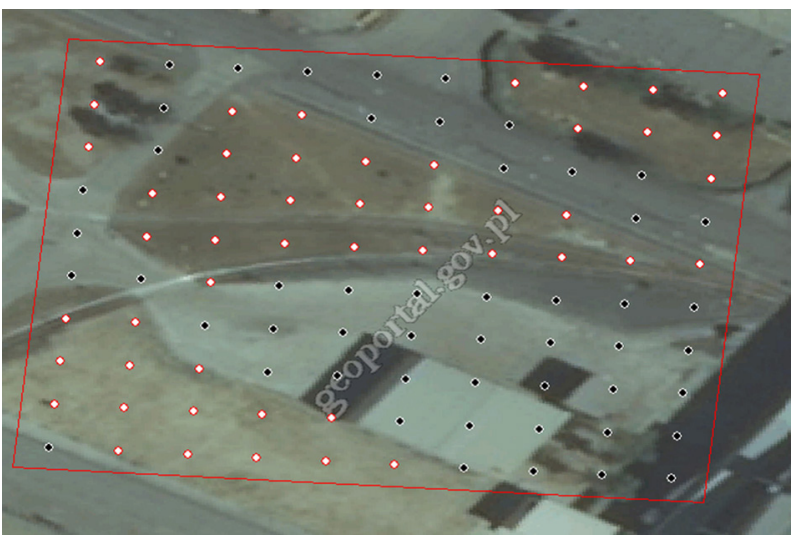

Fig. 4. Impervious surfaces misclassification (industrial area) SSL $-100 \%$, GT - 51\%.
Another problem observed in couple of samples is the confusion of two classes: impervious and semi-sealed. The classification algorithm does distinguish the category classes, especially in industrial areas (Fig. 4).

Another important factor increasing the possibility of low coherency between datasets is the time gap, despite the fact that the methodology applied was to avoid mistakes coming from land cover changes.

\section{Discussion}

A preliminary assessment of the SSL product was undertaken throughout the duration of the project. The evaluation was made in regard to Image 2000 and United States Geological Survey (USGS) datasets and proved that only $5 \%$ of the images didn't pass internal quality inspection (Müller et al. 2009a, 2009b).

Accuracy of SSL database was already calculated using Land Use/Cover Area-frame Survey (LUCAS) in 2010 for 11 countries, including Poland. The average value of sealing in SSE database was $3.15 \%$, but the LUCAS results were different: $5.7 \%$. Taking this outcome into consideration, it may be concluded that the SSE underestimates the level of imperviousness. In the more detailed analysis, the accuracy results of the particular classes proved similar to this study results: the classes with low degree of soil sealing present a grand underestimation, the middle classes proved to be more accurate, but the sealed class is overestimated by SSE. Spatial distribution of the underestimation and overestimation in comparison to CLC2000 was elaborated. The terrain of Poland is characterized by a significant underestimation of sealed areas (Gallego 2010).

The method of accuracy assessment, proposed by Hurbánek et al. (2010) was used for analogical research for other countries - Slovakia, Austria, Hungary, Switzerland, Italy and France (although the studies for these countries used smaller number of samples). The conclusions were similar, i.e.: overestimations appeared in larger soil sealing values in some countries, on the other hand, in most of the countries smaller sealing values were underestimated. Errors of larger magnitude were less frequent than errors of smaller magnitude. The most significant mistake was 
underrepresentation of small or dispersed settlements in rural areas (Hurbánek et al. 2010).

Overall accuracy of the product that was set by the authors is $\geq 85 \%$, along with the guidelines coming from European Environment Agency (EEA). This target value is widely used to accuracy assessment of remotely sensed imagery, although its application was sometimes undermined in literature (Foody 2008). However SSE data meet the objective, by achieving an overall accuracy of $85.58 \%$ (counting six intervals) or $99.47 \%$ (counting two intervals), the analysis proves that the results should be considered with caution.

It is also important to remind that the survey area did not cover the whole territory of Poland. Warsaw and Poznań surroundings were among the areas excluded from the research. Nevertheless validation proved that only a minor area of the country is characterized by high level of soil sealing. One of possible reasons of such a small number of cells in the highest interval can also be avoiding city-centres (due to the time gap between the SSL data and imagery available) while placing the random samples for the reference data.

Foody (2002) suggests that accuracy target value and method should be individually chosen for each classification, including the possibility of accuracy assessment for each class separately. A similar conclusion was derived in accuracy assessment study of SSE project for other countries (Hurbánek et al. 2010). Maucha et al. (2010) propose implication of $30 \%$ sealing threshold instead of $80 \%$ to order to achieve more precise assessment. The analysis of statistics calculated for SSE database implies, that accuracy for each class differs from the overall outcome, due to a great preponderance of natural surfaces.

One of the most common classification mistakes was made because the SSE algorithm confused sealed and semi-sealed classes. It was already mentioned in several studies, that semisealed surface definition is not clearly stated (Hurbánek et al. 2010).

Most project studies on accuracy have demonstrated that surfaces with low degree of soil sealing were largely underestimated. The analysis proves that the classification algorithm overlooks dispersed, small sealed surfaces. Also, the overestimation in high sealing level seems to come from the omission of small natural surfaces among the sealed areas. It is probably due to low ground resolution of the imagery, therefore, decreasing the pixel size in product updates might enhance the overall outcome.

\section{Conclusions}

The accuracy of the Soil Sealing Enhancement project for Poland can be described as fulfilling the criteria set by its authors. Nevertheless, it is worth noting that the classes are not equally numerous and that this feature affects the overall outcome. The natural class is characterized by the highest accuracy, but the intervals with bigger sealing level have obtained lower result. First sealed class contains a significant number of underestimated cells. Sealing level in next classes has generally been overestimated. Cohen'sKappa coefficient proves a low compatibility between the reference and classification dataset (according to Fleiss categorization).

Taking all the facts into consideration, the accuracy of Soil Sealing Enhancement for Poland can be treated as the maximum value of impervious surfaces. Further development of this automatic classification can eliminate causes of the high rate of commission errors without reducing precision. Using spatial imagery in greater spatial resolution and clearer distinction of the sealed and semi-sealed class can make an important factor to improve updates of the project. The small number of omission errors suggests that using higher spatial resolution may lead to more satisfactory results.

\section{References}

Brabec E., Schulte S., Richards P.L., 2002. Impervious surfaces and water quality: a review of current literature and its implications for watershed planning. Journal of Planning Literature 16: 499-514.

Congalton R.G., Green K., 1993. A Practical Look at the Sources of Confusion in Error Matrix Generation. Photogrammetric Engineering and Remote Sensing 59: 641-644.

European Commission, 2012a. Guidelines on Best practice to limit, mitigate or compensate soil sealing. Commission Staff Working Document, Brussels (http:// http://ec.europa. eu/environment/soil/pdf/soil_sealing_guidelines_ en.pdf/; accessed: 27 March 2014).

European Commission., 2012b. Soil Sealing, In-depth Report. Science for Environment Policy. DG Environment News Alert Service, Brussels (http://http://ec.europa.eu/ 
environment/archives/soil/pdf/sealing/Soil\%20Sealing\%20In-depth\%20Report\%20March\%20version_final. pdf; accessed: 15 March 2014).

European Environment Agency, 2006. Tender Specifications, GMES Fast Track Service on Land Monitoring, High Resolution Core Land Cover Data for Built-up Areas, Including Degree of Soil Sealing. EEA/IDS/07/001 (http://www. eea.europa.eu/about-us/tenders/EEAIDS07001/tender_specifications.pdf; accessed: 10 March 2014).

Flinker P., 2010. The Need to Reduce Impervious Cover to Prevent Flooding and Protect Water Quality. Rhode Island Department of Environmental Management, Rhode Island (http:/ / http:/ / www.dem.ri.gov/programs/bpoladm/ suswshed/pdfs/imperv.pdf/; accessed: 15 March 2014).

Foody G.M., 2002. Status of Land Cover Classification Accuracy Assessment. Remote Sensing of Environment 80: 185201 (http://http://www2.geog.ucl.ac.uk/ mdisney/ teaching/GEOGG141/papers/foody.pdf/; accessed: 15 March 2014).

Foody G.M., 2008. Harshness in image classification accuracy assessment. International Journal of Remote Sensing 29: 2137-3158 (http://eprints.nottingham.ac.uk/1995/1/ ePrints_-ijrs-HARSH.pdf/; accessed: 17 July 2014).

Gallego F.J., 2010. Validation of GIS Layers in the EU. International Journal of Digital Earth 4: 42-57.

Hurbánek P., Atkinson P.M., Pazur R., Rosina K., Chockalingam J., 2010. Accuracy of built-up area mapping in Europe at varying scales and thresholds. In: Tate N.J., Fisher P.F. (eds), Accuracy 2010: Proceedings of the Ninth International Symposium on Spatial Accuracy Assessment in Natural Resources and Environmental Sciences: 385-388 (http:/ / spatial-accuracy.org/ Accuracy2010; accessed: 17 July 2014).

Klosterman K.B., 2012. The Role of Structural Stormwater Best Management Practices, Impervious Surfaces and Natural Factors of Base Flow in Massachusetts (http://scholarworks. umass.edu/cgi/viewcontent.cgi?article=1858\&contex$\mathrm{t}=$ theses/; accessed: 17 July 2014).

Kopecky M., Kahaba H., 2006. Updated Delivery Report, European Mosaic. European Environment Agency. GMES Fast Track Service on Land Monitoring (http:/ / http:/ / www. eea.europa.eu/data-and-maps/data/eea-fast-track-ser- vice-precursor-on-land-monitoring-degree-of-soil-sealing/ eea-ftsp-degree-of-soil-sealing/ eea-ftsp-degree-ofsoil-sealing/download; accessed: 15 March 2014).

Maucha G., Büttner G., Kosztra B., 2011. European validation of GMES FTS Soil Sealing Enhancement data. European Environmental Agency. (http://www.eea.europa.eu/ data-and-maps/data/ eea-fast-track-service-precursoron-land-monitoring-degree-of-soil-sealing/eea-ftsp-degree-of-soil-sealing-1/soilsealing_european_validation_ finaldraf2t.pdf/download; accessed: 15 March 2014).

Müller R., Krauß T., Lehner M., Reinartz P., 2009a. Automatic Production of a European Orthoimage Coverage within the GMES Fast Track Service Using SPOT 4/5 and IRS-P6 LISS III Data. Wessling (http://citeseerx.ist.psu.edu/ viewdoc / download; jsessionid=F56CB0D38DFE7CB70076FC85A07646FB?doi=10.1.1.222.3875\&rep=rep1\&type=pdf/; accessed: 15 March 2014).

Müller R., Krauß T., Lehner M., Reinartz P., Frorsgren J., Rönnbäck G., Karlson A., 2009b. IMAGE2006 European Coverage, Methodology and Results. DLR IMF PB.

Polish Geoportal (http://geoportal.gov.pl; accessed: 30 March 2014).

Prokop G., 2012. Land Take and Soil Sealing: an Overview of the UE Situation. Paper presented at Soil Remediation and Soil Sealing Conference. European Commission, Brussels (http://ec.europa.eu/environment/archives/soil/ pdf/may2012/11\%20-\%20Gundula \%20Prokop $\% 20-\% 20$ final.pdf/; accessed: 15 March 2014).

Tóth G., 2006. Soil Function and Soil Sealing. European Commission Joint Research Centre, Institute for Environment and Sustainability, Land Management and Natural Hazard Unit (http://eusoils.jrc.ec.europa.eu/events/ SummerSchool_2006/Presentations/2_Toth_Soil\%20 functions $\% 20$ and $\% 20$ soil $\% 20$ sealing.pdf/; accessed: 15 March 2014)

Weng Q., 2007. Remote sensing of impervious surfaces. CRC Press, Taylor \& Francis Group, LLC.

Yang L., Huang C., Homer C.G., Wylie B.K., Coan M. J., 2003. An approach for mapping large-area impervious surfaces: synergistic use of Landsat-7 ETM+ and high spatial resolution imagery. Canadian Journal of Remote Sensing 29: 230-240. 